\title{
Expiratory flow limitation in divers
}

\section{To the Editor:}

The study of patterns of flow limitation in divers by TETZLAfF et al. [1] showed interesting results, suggesting that diminished flows at low lung volumes are associated with diving history. Whilst this is plausible, there is room for some doubt because of potential confounding and the statistics employed. The authors suggest that small differences in airway mechanics can be detected using midexpiratory flow at 25\% (MEF25) and 50\% (MEF50) vital capacity, but it is not clear whether this a true difference, attributable to differences in diving history.

One basic issue is that groups should ideally be matched for age and other confounders or at least that the lung function data should be corrected for differences in age and height before comparisons are made. For instance, control subjects are $\sim 4$ yrs younger and $1 \mathrm{~cm}$ taller which implies that on this account alone in control subjects values might be $0.17,0.16$ and $0.13 \mathrm{~L} \cdot \mathrm{s}^{-1}$ higher for mid-expiratory flow at $75 \%$ vital capacity (MEF75), MEF50 and MEF25, respectively, according to the European Coal and Steel Community (ECSC) reference values. Following adjustment for height and age, the between group differences may well lose statistical significance. Also, as age and years of diving are very highly correlated, one wonders whether the relationship between flow at low lung volume and years of diving will not vanish after correcting for differences in age. Furthermore, comparisons of flows make sense when assessed at similar absolute lung volumes (total lung capacity (TLC)) rather than at fixed percentages of the forced vital capacity (FVC). Differences between groups were considered significant if the likelihood that they were due to chance was $<5 \%$; we submit that when 16 lung function parameters are compared some downward adjustment of the 5\% level is in place. Obviously, different group characteristics and selection effects cannot be avoided, but they may partly explain differences in expiratory flows. The oxygen divers were slightly older, smoked less, were more often atopic and performed endurance sports more often, and had a longer diving history compared with control subjects. Age and atopy may reduce expiratory flows, unlike selection effects and less smoking. These factors may be hard to disentangle and conclusions may become more straightforward when smokers (and also exsmokers?) and atopics are excluded from the analyses. Ideally, expiratory flows are corrected for intrathoracic gas compression that may have more pronounced effects in subjects with larger airways resistance or those with greater expiratory muscle force. Oxygen toxicity may well affect airway wall mechanics in such a way that residual volume $(\mathrm{RV}) \% \mathrm{TLC}$ is increased (FVC reduced compared to vital capacity) and expiratory flows at low volumes are reduced, but age and increased compression of intrathoracic gas due to greater muscle force should also be considered.

We acknowledge that the putative relationship between (oxygen) toxicity and functional deterioration in divers merits further investigation. It would therefore be especially interesting to explore the results after matching or after adjustment of lung function data, for age and height, when flows are compared that are generated at similar lung volumes, and when either atopics and (ex)smokers are excluded from the analyses or groups have been made comparable with respect to these confounders.

\section{P.J.F.M. Merkus*, P.H. Quanjer ${ }^{+}$}

*Division of Respiratory Medicine, Dept of Paediatrics, Sophia Children's Hospital, Rotterdam, the Netherlands. Fax: 31 4636801. ${ }^{+}$Dept of Physiology, PO Box 9604, 2300 RC Leiden, the Netherlands.

\section{References}

1. Tetzlaff K, Friege IL, Reuter M, Haber J, Mutzbauer T, Neubauer B. Expiratory flow limitation in compressed air divers and oxygen divers. Eur Respir J 1998; 12: 895899.

\section{REPLY}

\section{From the authors:}

We appreciate the opportunity to address the questions raised by P.J.F.M. Merkus and P.H. Quanjer. In our article [1], we reported a pattern of lung function changes in air divers and oxygen divers that is consistent with small airways dysfunction. A decline of mid-expiratory flow at $25 \%$ (MEF25) and 50\% (MEF50) vital capacity was found to be associated with years of diving.

Merkus and Quanjer correctly state that groups (divers versus control subjects) should ideally be matched for age and other confounders. However, we compared samples of consecutively recruited subjects and found no statistically significant differences with respect to age and other confounders. Testing group differences with regard to these variables is a commonly performed practical solution when using that study design. We also compared absolute lung function values with the European Steel and Coal Community (ECSC) reference values. For MEF25, oxygen divers averaged $83.7 \%$ of predicted values, air divers $87.8 \%$ pred, and control subjects $101.5 \%$ pred. The differences 
between diving groups (oxygen divers and air divers) and control subjects were significant $(\mathrm{p}=0.006$ and $\mathrm{p}=0.005$, respectively). Following the suggestions by Merkus and Quanjer, we also applied Pearson's partial correlations between MEF25 and diving indices controlling for age and cigarettes. There was a significant inverse correlation between MEF25 and years of diving ( $\mathrm{p}=0.003)$.

According to the suggestions of Merkus and Quanjer we excluded current smokers and exsmokers as well as atopic subjects from re-analysis so that 15 oxygen divers, 71 air divers, and 17 control subjects remained. The formulae of Verdooren were again used for correction of different sample sizes. Mann-Whitney U-test revealed significant differences between air divers and control subjects with respect to MEF25 ( $\mathrm{p}=0.0042$ ). The former difference between oxygen divers and control subjects became insignificant.

In the study we tested particular hypotheses with respect to the distinct lung function values. According to SAVILLE [2], an $\alpha$-adjustment is not appropriate in that case. However, our findings should be confirmed in future studies.
In conclusion, even re-analysis of our data indicates evidence for an association between diving and endexpiratory flow limitation. We absolutely agree and point out that ideally divers' lung function should be surveyed in a longitudinal study involving a large sample size with matched control subjects, but this, however, has not been performed to date.

\section{K. Tetzlaff*, L. Friege ${ }^{+}$}

*Naval Medical Institute and Dept of Medicine I, and ${ }^{+}$Dept of Psychology, Christian-Albrechts-University of Kiel, Kiel, Germany. Fax: 4943154091778.

\section{References}

1. Tetzlaff K, Friege L, Reuter M, Haber J, Mutzbauer T, Neubauer B. Expiratory flow limitation in compressed air divers and oxygen divers. Eur Respir $J$ 1998; 12: 895899.

2. Saville DJ. Multiple comparison procedures: the practical solution. Am Statist 1990; 44: 174-180. 